European Society for Paediatric Research (ESPR)

\section{$\Delta 1$}

PLATELET-ACTIVATING FACTOR IS INVOLVED IN THE PATHOGENESIS OF NECROTIZING ENTEROCOLITIS IN ASPHYXIATED NEWBORN PIGLETS PROTECTIVE EFFECT OF BN 50727 AND BN 50730

Csongor S. Ábrahám, Judit Vágvölgyi, Thierry Tarrade, Mátyás Koltai, Balázs Gellén, József Kovács, Péter Temesvári, Sándor Pintér, Pierre Braquet

Departments of Pediatrics and Pathology, Albert Szent-Györgyi Medical University, Szeged, Hungary, and Institut Henri Beaufour, Le Plessis Robinson, France.

Necrotizing enterocolitis (NEC) is a life-threatening gastrointestinal complication in heonates. We investigated the effect of BN 50727 and BN 50730, two hetrazepine-type platelet-activating factor (PAF)-antagonists, on the development of NEC in asphyxiated hewborn piglets. Animals ( 3 groups, $n=8$ in each) were pretreated $1 \mathrm{~h}$ prior to the experiments with (1) BN 50727, (2) BN 50730, or (3) vehicle only (doses were 50 $\mathrm{mg} / \mathrm{kg}$ for both drugs in $5 \mathrm{ml} / \mathrm{kg}$ vehicle, in gastric tube). $1 \mathrm{~h}$ after the induction of bilateral pneumothorax, in the critical phase (arterial hypotension, bradycardia, hypoxaemia, and combined acidosis), the piglets were resuscitated and a $24 \mathrm{~h}$-recovery period was allowed to them. BN 50727 administration resulted in moderate decreases In postasphyxial tachycardia and hypertension, increased superior mesenteric artery flow, and improved oxygen saturation in the first hour of reperfusion. There were no similar changes in clinical parameters after BN 50730 treatment. Both PAF-antagonists jignificantly $(p<0.001)$ reduced the degree of histological injuries, determined by the tmodified method of Schneider $e$ t al (1987; Pediatr Res 21:422), in the crypts and villi of small intestine (duodenum, jejunum, ileum) of piglets $24 \mathrm{~h}$ after the asphyxia. In conclusion, BN 50727 and BN 50730 have a protective effect during neonatal NEC.

\section{2}

ANALYSIS OF METHYLATION PATTERN IN FEMALES WITH LOW FACTOR VIH:C LEVEL

Maura Acquila,Daniela Caprino,Patrizia Bicocchi, Crocifissa Lo Cunsolo C, Pier G. Mor Maura Acquila,Daniela Caprino,Patrizia Bicocchi, Crocifissa Lo Cunsolo C, Pier G. Mori
Department of Pediatric Hematology/Oncology, G. Gaslini Children's Research Hospital, Genova (Italy)

The analysis of $X$ chromosome activation through the metilation pattern could be useful in the study of affected females for $X$-linked recessive diseases, such as Hemophilia A (HA). Low FVIII:C level in female can be due to: acquired inhibitors to FVIII, $X$ chromosom abnormalities, homozygosity at the hemophilia locus, extreme lyonization in an heterozygote. It is possible to reveal a non random inactivation of $X$ chromosomes by hybridization of genomic DNA with M27B probe (locus DXS 255). We analyzed with this probe 3 females with low FVIII:C levels (range 2\%-5\%). G.V. is a 33 year old female (FVIII:C $5 \%$, FVIIIVW:A $80 \%$ ) born from a HA carrier and a normal man. Karyotype was $46, X X$ and no inhibitors against FVIII were detected. The study with M27B probe showed that only the patemal $X$ chromosome was inactive. HA in this female is probably due to a non random $X$-inactivation. P.M. is a 48 year old female (FVIII:C $12 \%$; FVIIIVW:Ag 100\%) bom from first cousins parents. Her father and brother are hemophilics (FVIII:C 11\%) and her mother was a carrier. Cytogenetic studies revealed no abnormalities. M27B analysis showed a balanced lyonization. An homozygosity for the HA defective gene, was demonstrated by the aplotype analysis with An homozygosity for the HA defective gene, was demonstrated by the aplotype analysis with RFLPS. P.T. is a 19 year old female (FVIII:C $2.2 \%$; FVIIIVW:Ag $73 \%$ ) with Turner Syndrome
(46,X,-idic $(X)$ ) bom from healthy unrelated parents without history of bleeding disorders. The $(46, X$,-idic $(X))$ born from healthy unrelated parents without history of bleeding disorders. The RFLP studies showed the maternal origin of idic $(X)$. The methylation pattern obtained by $M 27 B$ probe confirmed the whole inactivation of the abnormal $X$ therefore we hypothesized a mutation in FVIII gene in the normal $X$ coming from her heaithy father. In conclusion, the
possibility to demonstrate the degree of $X$-chromosome activation is a very important and useful tool in understanding the pattern of HA carriers.
$\Delta 4$

NITRIC OXIDE IMPROVES OXYGBNATION IN NEONATES WITH RBSPIRATORY DISTRESS SYNDROME AND PULMONARY HYPERTENSION J Ahluwalial, A Kelsall1, J Raine ${ }^{1}$, R Rennie $^{1}, \mathrm{~J}^{1}$ Pickett ${ }^{2}, \mathrm{~N}$ Mahmood2, A Octuro $^{2}$, R Latimer ${ }^{2}$, T Higgenbottam ${ }^{2}$. $1_{\text {NICU, Rosie }}$ Maternity Hospital and 2papworth Hospital, Cambridge, UK. Aim To investigate whether inhaled nitric oxide (NO) improves oxygenation in neonates with respiratory distress syndrome (RDS) and secondary pulmonary hypertension. Methods no given at 20 , 40, 80 parts per million for 1 hour each. NO and NO2 measured using chemiluminescence. Ventilation altered to maintain $\mathrm{PaO} 2$ between 7 and $10 \mathrm{kPa}$ and $\mathrm{PaCO} 2$ between 4 and $6.5 \mathrm{kPa}$. Estimation of pulmonary artery pressure (PAP) made with Doppler. Bleeding time and methaemoglobin (Met) measured.

Result

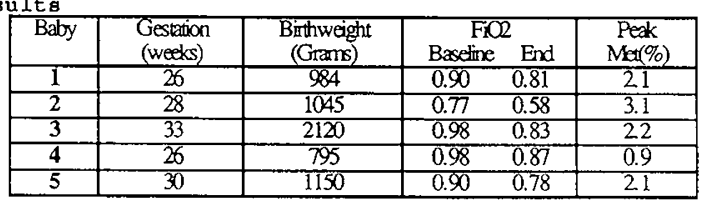

PAP, systemic blood pressure and bleeding time were unchanged. No rise in NO2 seen. Conclusions NO can be administered safely to preterm infants with encouraging results from pilot studies.

\section{3}

COMPUTBR-CONTROLLBD VENTILATION OF PRETERM INFANTS USING SPONTANBOUS INSPIRATORY \& BXPIRATORY TIMBS. Jagjit $S$ Ahluwalia, Jeffrey NA Mockridge, Colin J Morley. Dept Paediatrics, Addenbrooke's Hospital, Cambridge, UK. Aim To assess whether computer-controlled ventilation (CCV) can ventilate infants with RDS. Methods A Graseby capsule at the sub-xiphisternum detects diaphragmatic contraction. Software analyses the signal, removes artefact, calculates spontaneous inspiratory (Ti) and artefact, calculates spontaneous inspiratory (Ti) and expiratory times ( $\mathrm{Te}$ ) and uses these to control the
ventilator continuously so the ventilator and infant cycle ventilator continuously so the ventilator and infant cycle together. Patients 14 babies were studied: median (range)
gestation $28(25-33)$ weeks, birthweight 1118 (561-2120) grams, $\mathrm{FiO}_{2} 0.45(0.28-0.95)$, peak pressure (PIP) 17 (1423) $\mathrm{cm}$ water. Results CCV was used for $15(3-142)$ hours per infant. Normal blood gases were maintained.

\begin{tabular}{|c|c|c|} 
& $\begin{array}{c}\text { Averaged data per } \\
\text { infant: median (range) }\end{array}$ & $\begin{array}{c}\text { Instantaneous min and } \\
\text { max from any baby }\end{array}$ \\
\hline Rate (bpm) & $73(60$ to 88$)$ & 46 and 130 \\
\hline $\mathrm{Ti}(\mathrm{sec})$ & $0.28(0.26$ to 0.34$)$ & 0.20 and 0.48 \\
\hline $\mathrm{Te}(\mathrm{sec})$ & $0.53(0.42$ to 0.70$)$ & 0.24 and 0.92 \\
\hline
\end{tabular}

Six infants were weaned by pressure reduction while the infant controlled the rate. In these infants nasal CPAP was started when PIP was $11(10-15) \mathrm{cm}$ water, and the rate was $54 \mathrm{bpm}(50-70)$. No infant was reventilated.

Conclusion $\mathrm{CCV}$ was successful at ventilation and weaninä.

\section{5}

Brigitte C. Ahrens, Sebastian Buttenberg, Roland R. Waver

Dept. of Neonatology, Univ.-Kinderklinik Charité, 10098 Berlin, Germany LUNG FUNCTION TESTING(LFT) IN UPPER AIRWAY OBSTRUCTION (UAO) AND FLEXIBLE BRONCHOSCOPY (FB) IN PRETERM AND TERM INFANTS * Typical deformation of tidal breathing flow-volume-loops
(TBFV) and passive expiration loops (single breath occlusion technique) are suspicious of UAO. FB identifies the pathoanatomic structure. Aim of the study was to determine the usefulness of LFT for identification and follow-up of UAO. Methods: The UAO was initially verified by LFT, FB, chest X-ray, blood-gas-analysis. In certain cases CT-Scanning or angiography were included. LFT was performed with SensorMedics 2600 , USA. FB (Olympus BF-N20, Japan) was executed bedside through nostril or endotracheal tube after sedation. Indication for LFT/FB was hoarseness, cough, stridor. From $4 / 93$ to $2 / 94$ ten infants were studied in the neonatai intensive care unit. At first LFT/FB actual weight was $3840 \mathrm{~g}$ (median), $1760 \mathrm{~g} / 8400 \mathrm{~g}(\mathrm{~min} / \mathrm{max}) ;$ age 30 days (median), $4 / 311$ (min/max).4 infants had congenital malformations (3 oesophageal atresia, 1 vascular malformation), 6 acquired lesions (4 post intubation, 2 infections). Results: TBFvloops and passive expiratory loops show typical alteration with UAO. FB confirmed subglottic stenosis(3), laryngeal (3) and tracheal malacia(4). In serial LFT's restitution can be demonstrated. Conclusion: LFT is valuable for detection and follow-up in UAO, FB can be planned according to the LFT results. "supparted by expr grat "Risikanangebanen"

\section{$\Delta 6$}

HUMAN FETAL CEREBRAL OXYGEN SATURATION ( $\left.\mathrm{SmCO}_{2}\right)$ MEASURED DURING I.ABOUR CAN PREDICT ACID-BASE STATE AT DELIVERY.

Clive J. Aldrich, Donato D'Antona, John $S$. Wyatt, John $A$. D. Spencer, Donald M. Peebles, David T. Delpy, E. Osmund R. Reynolds. Departments of Paediatrics and obstetrics, University College London Medical School, London

If the exchange of oxygen and carbon dioxide between the maternal and fetal circulations is interrupted during labour, fetal acidosis may occur. The purpose of this study was to assess the relation between $\mathrm{SmcO}_{2}$ determined by near infrared spectroscopy (NIRS) within the last 30 minutes of labour and umbilical cord blood acid-base status measured immediately at birth. A specially designed optical probe was inserted through the dilated cervix and placed against the fetal head $(n=41)$. Changes in cerebral oxyhaemoglobin and deoxyhaemoglobin concentrations were measured continuously in each fetus to within 20 minutes of delivery (mean 11 minutes). In 33 fetuses it was possible to calculate a mean value for $\mathrm{SmCO}_{2}$ over a 10 minute period of $46 \%$ (range 21-71\%). There was a statistically significant positive correlation between $\mathrm{SmcO}_{2}$ and both the umbilical artery $\mathrm{pH}$ (range 7.09-7.43) $(x=0.82, \mathrm{p}<0.001)$ and base excess (range -11.0 to $\left.0.7 \mathrm{mmol} . \mathrm{L}^{-1}\right) \quad(r=0.73, p<0.001)$. We conclude that $\mathrm{SmCO}_{2}$ measured within 30 minutes of delivery is related to fetal acid-base balance at birth. 